\title{
Does laser surface texturing really have a negative impact on the fatigue lifetime of mechanical components?
}

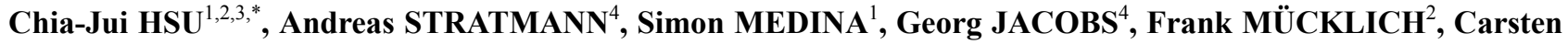 \\ GACHOT $^{1}$ \\ ${ }^{1}$ Institute for Engineering Design and Product Development, TU Wien, Lehárgasse 6, Campus Getreidemarkt, Vienna 1060, Austria \\ ${ }^{2}$ Chair of Functional Materials, Saarland University, Campus D3.3, Saarbrücken 66123, Germany \\ ${ }^{3}$ AC2T Research GmbH, Viktor-Kaplan-Straße 2/C, Wiener Neustadt 2700, Austria \\ ${ }^{4}$ Institute for Machine Elements and Systems Engineering, RWTH Aachen, Schinkelstraße 10, Aachen 52062, Germany \\ Received: 28 October 2020 / Revised: 15 December 2020 / Accepted: 19 March 2021 \\ (C) The author(s) 2021.
}

\begin{abstract}
Laser surface texturing (LST) has been proven to improve the tribological performance of machine elements. The micro-scale patterns manufactured by LST may act as lubricant reservoirs, thus supplying oil when encountering insufficient lubrication. However, not many studies have investigated the use of LST in the boundary lubrication regime, likely due to concerns of higher contact stresses that can occur with the increasing surface roughness. This study aims to examine the influence of LST on the fatigue lifetime of thrust rolling bearings under boundary lubrication. A series of periodic patterns were produced on the thrust rolling bearings, using two geometrically different designs, namely cross and dimple patterns. Base oil ISO VG 100 mixed with $0.05 \mathrm{wt} \% \mathrm{P}$ of zinc dialkyldithiophosphate (ZDDP) was supplied. The bearings with cross patterns reduce the wear loss by two orders of magnitude. The patterns not only retain lubricant in the textured pockets but also enhance the formation of an anti-wear tribofilm. The tribofilm generation may be improved by the higher contact stresses that occur when using the textured surface. Therefore, in contrast to the negative concerns, the ball bearings with cross patterns were instead found to increase the fatigue life by a factor of three.
\end{abstract}

Keywords: thrust rolling bearing; laser surface texturing; direct laser interference patterning; zinc dialkyldithiophosphate (ZDDP); tribofilm

\section{Introduction}

The occurrence of pitting failure often limits the lifetime of machine components operating under rolling/sliding contacts, such as bearings and gears. Rolling contact fatigue (RCF) is initiated by micro-cracks, and the growth of cracks eventually leads to surface pitting and failures. Pitting failures can be categorized by the location of the micro-cracks: either in the sub-surface zone or on the surface of the material. Sub-surface failures have become less frequent due to improvements in steelworks, which has decreased the amount of inclusions [1]. However, surface-initiated pitting, which begins with cracks initiated by defects, wear debris, or asperities on the surface, has caused a rising percentage of failures in modern applications [2]. This is attributed to the lower thickness of oil film that occurs when pursuing increased efficiency via reducing lubricant viscosity or adopting higher machining power, which makes the machine components operate in severe lubrication conditions, namely the boundary lubrication regime. Boundary lubrication is defined as the regime with a small ratio of the oil film thickness to the mean roughness value, and is mostly associated

* Corresponding author: Chia-Jui HSU, E-mail: chia-jui.hsu@tuwien.ac.at 
with a high load and a low sliding speed, where only monolayers of a lubricant cover the interacting surfaces [3, 4]. In principle, wear is unavoidable in this lubrication regime, and wear debris can further damage the surface, which promotes the initiation of pitting [5]. Consequently, surface engineering and anti-wear tribofilms are recommended, to enhance wear resistance in boundary lubrication [6-9].

Novel methods of surface engineering, such as laser surface texturing (LST), have been proven to be beneficial for the tribological performance [10]. It is suggested that LST provides positive contributions in every lubrication condition, from the boundary to the hydrodynamic regime [11, 12]. The unique topography of the laser patterns can retain lubricants in the contact zone, thus providing the necessary lubrication when external supply is insufficient. In addition, the space within patterns can trap harmful wear debris in the valleys and prevent them from causing further damage on the contacting surfaces [6]. Laboratory tests have demonstrated promising improvements to tribological performance. LST has been evaluated and shown to decrease wear and friction in industrial applications such as roller bearings [13], ball bearings [14], valves [15], and pistons [16]. In case of conformal contacts, many studies have highlighted positive results by texturing with the area coverage between $10 \%-30 \%$. In case of non-conformal contacts, smaller sizes and shallower depths (around $1 \mu \mathrm{m}$ or less) have led to better performances [7]. Nevertheless, further experimental results using LST are required to fully determine the limitation and the applicability of LST.

Another approach to avoiding direct contact in the boundary lubrication regime is to generate a protection layer. The so-called anti-wear tribofilm is usually produced by the introduction of certain lubricant additives. Zinc dialkyldithiophosphate (ZDDP), which is one of the most popular oil additives, was used in this study. It has been shown that the presence of the ZDDP tribofilm reduces wear [17-19]. The layer is often described as an island-like thin-film, with a thickness of around $100 \mathrm{~nm}$ and width from 0.5 to several micrometers $[8,20]$. The origin of the layer formation is the energy input to the contact area [21], driven by shear and temperature. Moreover, the growth of the tribofilm is confirmed to be more efficient when induced by tribological/shearing action [22].
Compared to the film generated only by temperature, the shear-induced tribolayer is more stable and has better wear resistance [17].

According to previous studies, the combined use of LST and anti-wear tribofilm reduces sliding induced damage [7, 23-26]. Rosenkranz et al. tested and confirmed the enhancement of the frictional performances on thrust roller bearings with dot patterns $[12,13]$. Hsu et al. have found a fully formed ZDDP tribofilm at the topographical maximum of a periodic laser pattern, indicating an enhancement of the formation of ZDDP tribofilm by direct laser interference patterning (DLIP) [27]. Furthermore, the proven ability of surface protection by LST can further reduce fatigue failures. As an illustration, the fatigue lifetime of roller bearings under elastohydrodynamic lubrication was increased by mechanical surface texturing [28]. However, to the best of our knowledge, there is still no fatigue study under boundary lubrication considering laser textured samples. Therefore, this study aims at evaluating the fatigue lifetime of laser textured rolling bearings. Four different patterns geometry designs were initially tested for performance in terms of wear, and the best of these designs were used for the subsequent fatigue tests. The results are statistically analyzed by Weibull distribution. Finally, the effect of the laser patterns on the contact pressure distribution has been examined through contact simulation models.

\section{Experiments and methods}

\subsection{Laser surface texturing}

Two geometrically different LST patterns were tested in the present study: dimple and cross patterns. Samples were cleaned by ethanol and isopropanol before laser treatments. The surface preparation details can be found in Table 1, and the schematic of the LST pattern is shown in Fig. 1.

The dimple patterns with a depth of approximate $0.9 \mu \mathrm{m}$ and a diameter of $30 \mu \mathrm{m}$ were manufactured by a Ti-sapphire femtosecond pulsed laser (Spitfire Pro, Spectra Physics). The laser was applied with a wavelength of $800 \mathrm{~nm}$, a frequency of $1 \mathrm{kHz}$, and a pulse duration of $150 \mathrm{fs}$. Each dimple was created from one laser pulse by using a controlled shutter. 
Table 1 Experimental details of the patterns by laser surface texturing.

\begin{tabular}{|c|c|c|c|c|c|}
\hline Samples & $\begin{array}{l}\text { Peak } \\
\text { energy } \\
\left(\mathrm{J} / \mathrm{cm}^{2}\right)\end{array}$ & $\begin{array}{c}\text { Pulse } \\
\text { duration }\end{array}$ & $\begin{array}{l}\text { Pattern } \\
\text { type }\end{array}$ & $\begin{array}{l}\text { Periodicity } \\
\quad(\mu \mathrm{m})\end{array}$ & $\begin{array}{c}\text { Height } \\
(\mu \mathrm{m})\end{array}$ \\
\hline Dimple500 & 12.7 & $150 \mathrm{fs}$ & Dimple & 500 & 0.9 \\
\hline Dimple200 & 12.7 & $150 \mathrm{fs}$ & Dimple & 200 & 0.9 \\
\hline Cross9 & 1.2 & $10 \mathrm{~ns}$ & Cross & 9 & 1.1 \\
\hline Cross 30 & 1.2 & $10 \mathrm{~ns}$ & Cross & 30 & 1.1 \\
\hline
\end{tabular}

Fig. 1 A schematic of the profile of the laser textured surface in the lubricated contact condition; $h$ shows the height from the valley to top, $d$ shows the diameter of the holes or the ditches, and $p$ shows the distance of the periodicity.

The applied energy fluence was measured as $12.7 \mathrm{~J} \cdot \mathrm{cm}^{-2}$. The texturing position on the surface was manipulated by a programmable $x-y$ motion controller, which moves the stage to the required position with a synchronized link to the laser shutter. The periodic distance between dimples was set as 200 and $500 \mu \mathrm{m}$. The parameters have been proven for friction reduction under the boundary lubrication regime [11]. It is noted that the stepping resolution of the stage movement in the $x$ direction was limited, and this resulted in alternating 160 and $240 \mu \mathrm{m}$ distances between dimples when setting the periodicity as $200 \mu \mathrm{m}$. Nevertheless, the average periodicity was measured as $200 \mu \mathrm{m}$.

Moreover, cross patterns were produced by DLIP, which uses interference for LST. A Nd:YAG nanosecond pulse laser (Quanta Ray Pro 290, Spectra Physics) was used with a wavelength of $532 \mathrm{~nm}$, a pulse frequency of $10 \mathrm{~Hz}$, and a pulse duration of $10 \mathrm{~ns}$. The applied energy fluence was measured as $1.2 \mathrm{~J} \cdot \mathrm{cm}^{-2}$. The primary laser beam was split into two sub-beams by a
50/50 beam-splitter. Subsequently, the two sub-beams were superposed onto the surface with a certain incident angle, which creates the interference patterns. The incident angle is used to control the periodic distance of the line patterns. The cross pattern can be finally produced by an additional laser shot at the same position with a $90^{\circ}$ of rotation. More details of the DLIP setup can be found in the previous study [29]. Furthermore, the surface topography was then evaluated by using a white light interferometer (WLI, Zygo NewView 7300).

\subsection{Rolling bearing test rig}

A test rig FE8 according to DIN51819-1 was used for both an initial wear evaluation of all four textures plus reference sample, and then for a fatigue lifetime assessment of the best-performing textured sample (that showed minimum wear). For the initial wear tests, commercial thrust cylindrical roller bearings (Type 81212) were installed with a horizontal axis of rotation. The bearings are made of steel 100Cr6 (AISI 52100), and the roughness $R_{a}$ of the washers was measured as $0.06 \mu \mathrm{m}$. The LST patterns were manufactured onto the surfaces of the bearing washers. Base oil ISO VG 100 mixed with ZDDP as an additive of C3C4-alkyl-chain with $0.05 \mathrm{wt} \% \mathrm{P}$ was used in a 2 hours test; the load, rotational speed, and working temperature were set as $80 \mathrm{kN}, 20 \mathrm{rpm}$, and $60{ }^{\circ} \mathrm{C}$, respectively. The lubrication condition based on the film thickness was calculated according to Dowson et al. [30, 31]. The lambda values of the experiments were between 0.04 and 0.12 , indicating that all the tests were conducted under boundary lubrication conditions [32]. Further information on the experiments can be found in Table 2. After the test, the surface was rinsed with benzene and isopropanol to clean the residual oil, abrasives, and contaminants. The wear tracks were measured by WLI.

For the fatigue lifetime evaluation, thrust ball bearings (Type 51212) were used in place of the roller bearings. Despite the plane surface of the roller bearings being more suitable for LST, ball bearings

Table 2 Experimental details and lubricant properties of the tribological tests by using an FE8 test rig.

\begin{tabular}{ccccccc}
\hline \multicolumn{3}{c}{ Experimental parameters } & & & \multicolumn{3}{c}{ Oil properties at $60{ }^{\circ} \mathrm{C}$} \\
\cline { 1 - 2 } Rolling speed & Max. pressure & Temp. & & Kinematic viscosity & Density & Pressure-viscosity coefficient \\
\hline $0.04 \mathrm{~m} / \mathrm{s}$ & $1.92 \mathrm{GPa}$ & $60{ }^{\circ} \mathrm{C}$ & & $38.3 \mathrm{~mm}^{2} / \mathrm{s}$ & $869.1 \mathrm{~kg} / \mathrm{m}^{3}$ & $1.82 \times 10^{-8} \mathrm{~Pa}^{-1}$ \\
\hline
\end{tabular}


were chosen to avoid wear loss by shearing. The rolling motion of the balls features only a small amount of sliding (in comparison to the cylindrical rollers), and thus minimizes abrasive and adhesive wear. This helps ensure that the fatigue life would predominantly be determined by pitting failure alone.

The same test rig and the same ZDDP-containing oil were used. The test conditions were set as $80 \mathrm{kN}$, $750 \mathrm{rpm}$, and $90{ }^{\circ} \mathrm{C}$, thus a significant increase in rotational speed compared to the initial tests but maintaining the same applied load. The tests were stopped as soon as surface damage (either on a ball or a washer) was detected by a vibration sensor. Further information on the fatigue experiments can be found in Table 3.

\subsection{Contact simulation}

The normal contact between each bearing surface and a roller was modelled, using boundary elements, to estimate the contact pressures and contact areas for each different surface pattern. The analysis used a 3D surface profile of the textured and reference samples, with a smooth cylindrical roller counterbody. The model assumes a homogeneous half-space for each surface and uses an iterative conjugate-gradient method to obtain valid contact pressures for the imposed loading [33].

A 3D profile of a section of the textured or reference bearing surface was measured using WLI to provide a representative surface for analysis of $640 \times 480$ nodes. Since the measured surface area did not enclose the full roller-washer contact, the measured surface was expanded by mirroring and tiling the surface profile data. This helps avoid edge effects at the ends of the roller (or solution domain) while maintaining realistic contact behavior. Results for the contact pressures and contact area were subsequently obtained over the original, as-measured profile only. The simulation was restricted to an elastic analysis without any plasticity considerations; whilst this does lead to some excessive localized pressures, it does enable an appropriate comparison of the extent of loading stresses without complications associated with the hardness of the laser-modified surfaces.

\section{Results and discussions}

\subsection{Morphology of the laser textured surfaces}

The surface topography profiles of the LST patterns are shown in Fig. 2, and the details of the profile are listed in Table 1 . The dimple patterns produced by femtosecond pulsed laser are shown in Figs. 2(a) and 2(b). The dimples are distributed with a periodicity of 500 and $200 \mu \mathrm{m}$, whereas the cross patterns are shown in Figs. 2(c) and 2(d) with periodicity of 9 and $30 \mu \mathrm{m}$. The samples are subsequently referred to as Dimple500, Dimple200, Cross9, and Cross30, respectively. Further, the profile is similar to a sine wave with a height of approximately $1 \mu \mathrm{m}$. The roughness parameters listed in Table 4 show an increase of surface roughness by LST for all geometries. The patterns with shorter periodic distance have greater values of $S_{a}$ and $S_{\text {q. }}$. Since the LST structural height is larger than the untextured roughness, the higher concentration of patterns increases the mean roughness value, which theoretically causes higher contact stress. However, the capacity of lubricant storage may not be directly obtained by the mean roughness values such as $S_{\text {a }}$. Additional topographical parameters were thus calculated to describe the ability of lubricant storage.

The bearing ratio curve, which is also known as Abbott-Firestone curve, represents the height distribution of the laser patterns in Fig. 3. The curves of the dimple patterns (see Fig. 3(a)) have a similar shape to the untextured reference surface, which indicates a geometrical similarity. This is expected because the surface is only modified at dimple locations and most of the surface remains nearly unchanged. However, the higher value at both ends represents a larger volume near the topographical maximum and minimum, caused by concentrated sharp edges of the dimples. Therefore, shorter LST periodic distance was associated with greater values of $S_{\mathrm{pk}}$ and $S_{\mathrm{vk}}$. In contrast, the bearing ratio curves of the cross patterns,

Table 3 Experimental details and lubricant properties of the fatigue tests by FE8 test rig.

\begin{tabular}{ccccccc}
\hline \multicolumn{3}{c}{ Experimental parameters } & & & \multicolumn{3}{c}{ Oil properties at $90{ }^{\circ} \mathrm{C}$} \\
\cline { 1 - 1 } Rolling speed & Max. pressure & Temp. & & Kinematic viscosity & Density & Pressure-viscosity coefficient \\
$1.53 \mathrm{~m} / \mathrm{s}$ & $3.5 \mathrm{GPa}$ & $90{ }^{\circ} \mathrm{C}$ & & $13.6 \mathrm{~mm}^{2} / \mathrm{s}$ & $850.8 \mathrm{~kg} / \mathrm{m}^{3}$ & $1.50 \times 10^{-8} \mathrm{~Pa}^{-1}$ \\
\hline
\end{tabular}



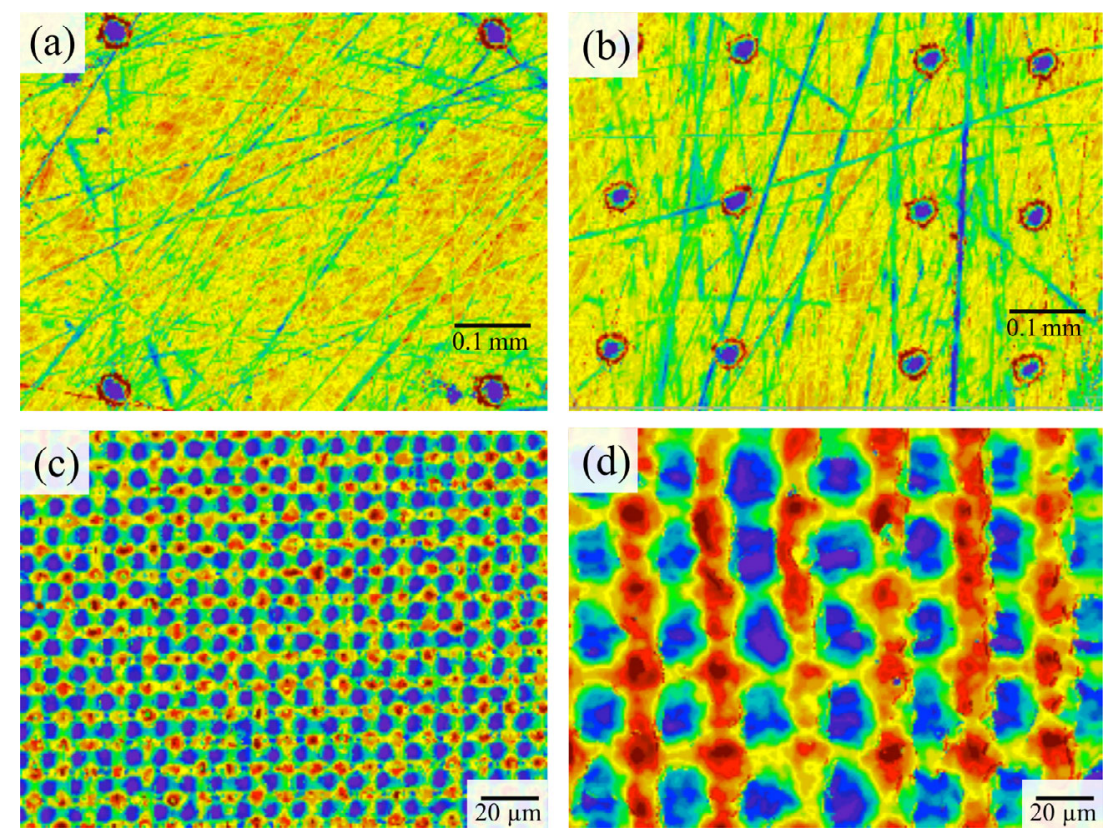

Fig. 2 Surface topography profiles of the LST patterns on the washers of bearings. The dimple pattern was made by femtosecond pulsed laser with a periodicity of (a) $500 \mu \mathrm{m}$ and (b) $200 \mu \mathrm{m}$; the cross pattern was made by DLIP with a periodicity of (c) $9 \mu \mathrm{m}$ and (d) $30 \mu \mathrm{m}$.

Table 4 Roughness and bearing ratio parameters of the surface by laser surface texturing* ${ }^{*}$.

\begin{tabular}{ccccccccc}
\hline & $S_{\mathrm{a}}$ & $S_{\mathrm{q}}$ & $S_{\mathrm{k}}$ & $S_{\mathrm{pk}}$ & $S_{\mathrm{vk}}$ & $A_{\mathrm{p}}$ & 0.003 \\
\hline Reference & 0.06 & 0.08 & 0.18 & 0.12 & 0.11 & 0.30 & 0.008 & 0.006 \\
Dimple500 & 0.09 & 0.16 & 0.13 & 0.33 & 0.46 & 0.45 & 0.015 & 0.013 \\
Dimple200 & 0.15 & 0.25 & 0.24 & 0.28 & 0.20 & 0.008 & 0.008 \\
Cross9 & 0.32 & 0.39 & 1.04 & 0.27 & 0.18 & 0.007 \\
Cross30 & 0.27 & 0.33 & 0.68 & 0.007 \\
\hline
\end{tabular}

*All values are shown in $\mu \mathrm{m}$.

$S_{\mathrm{a}}$-Arithmetic average height; $S_{\mathrm{q}}$ - Root mean square deviation; $S_{\mathrm{k}}$-Core roughness depth; $S_{\mathrm{pk}}$ - Reduced peak height; $S_{\mathrm{vk}}-$ Reduced valley depth; $A_{\mathrm{p}}$ - Material volume in peak zone; $A_{\mathrm{v}}$-Void volume in valley zone.

shown in Fig. 3(b), indicate a clear difference to the reference samples. The slopes are higher compared to the dimples, indicating a larger topographical variation over the total surface. Compared to the dimple patterns, which were still similar to the reference surface, the cross patterns had modified the surface more significantly.

In Table 4, the dimple patterns present larger values of $S_{\mathrm{vk}}$, the valley height of the profile, whereas the cross patterns show greater values of $S_{k}$, the core height of the profile. It has been suggested that the $S_{\mathrm{vk}}$ value extracted from a bearing ratio curve is a suitable index of the ability for lubricant storage [34]. An increase of $S_{\mathrm{vk}}$ indicates a larger valley area, which provides space that acts as a reservoir. When comparing only $S_{\mathrm{vk}}$ values, the dimple patterns could retain more lubricant than the cross samples. However, when the overall geometry differs between the two pattern types, the assessment of lubricant storage should involve both $S_{\mathrm{k}}$ and $S_{\mathrm{vk}}$. Therefore, the possible storage space within the core height $S_{\mathrm{k}}$ can be also inlcuded. It is noted that the values of peak and valley area, $A_{\mathrm{v}}$ and $A_{\mathrm{p}}$, show a similar tendency to the $S_{\mathrm{pk}}$ and $S_{\mathrm{vk}}$ values.

\subsection{Wear performances of LST samples}

In Fig. 4, the mass and volume loss of the bearing after testing is shown, revealing the extent of wear of the bearings. The volume loss is an average value obtained from WLI measurements. It can be seen that all of the laser patterns showed less wear loss than the untextured pristine specimens, which can be 

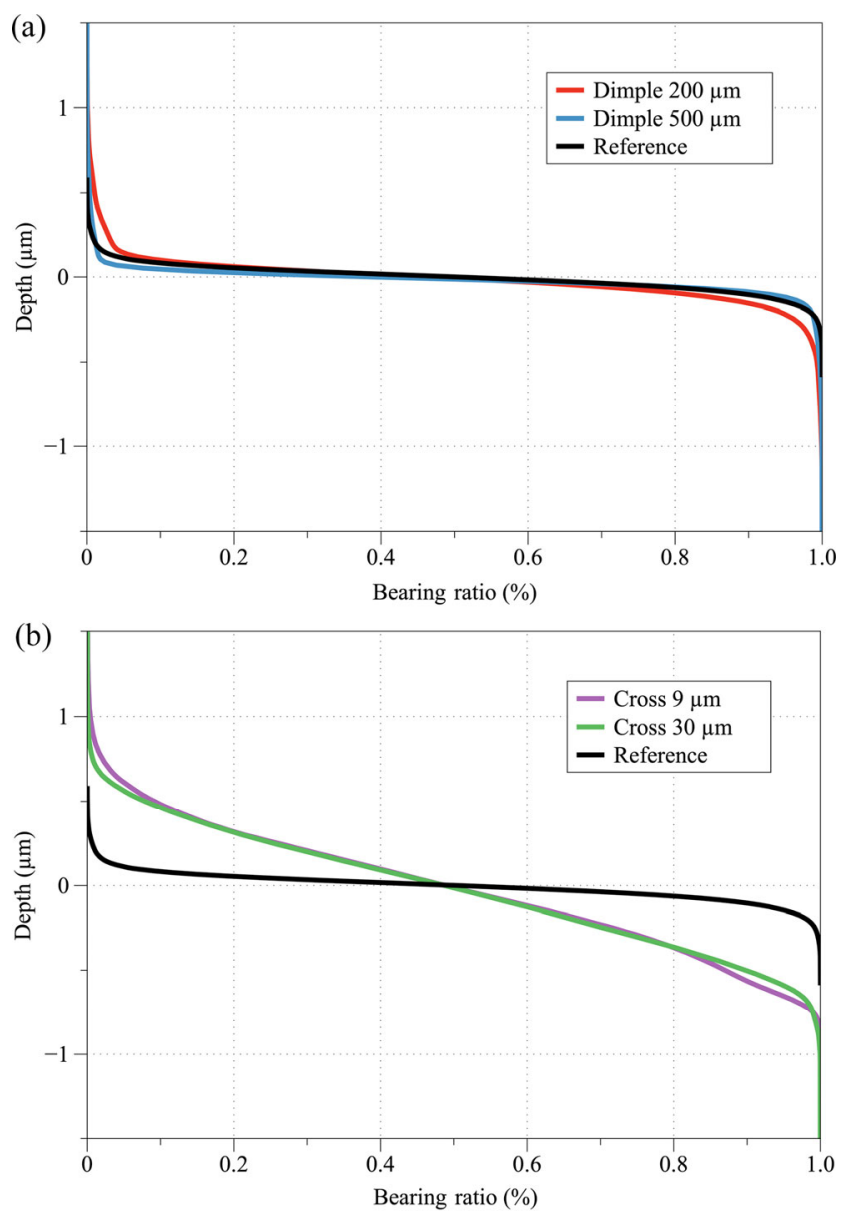

Fig. 3 The Abbott-Firestone curves of (a) the dimple patterns by femtosecond pulsed laser with a periodicity of 200 and $500 \mu \mathrm{m}$; (b) the cross patterns by DLIP with a periodicity of 9 and $30 \mu \mathrm{m}$.

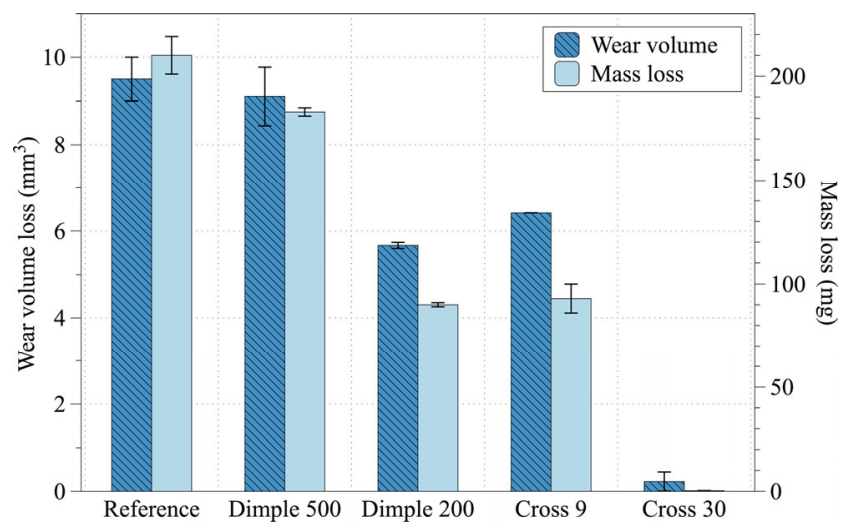

Fig. 4 Wear measurement of the bearings after tribotests in volume loss and mass loss.

attributed to the lubricant storage capability of the textured surface. Only mild wear was measured on sample Cross30, which indicates a significant wear protection by LST.

The sample Cross30 has a wear reduction of two orders of magnitude compared to all the other samples. The reasons for this significant reduction are presumably due to two points. Firstly, the surface patterns act as lubricant reservoirs, which supports lubrication when encountering starved situations. Both types of patterns can retain lubricants in the valleys, but the cross patterns have an increased capacity, which was shown by the aforementioned bearing ratio curve. Secondly, a fully-established ZDDP antiwear tribofilm was observed on the Cross30 sample. The tribofilm can be also found on Cross9 and Dimple200, but the wear tracks were only partially covered by the protecting tribofilm due to a higher wear rate, since the antiwear mechanism is in a dynamic equilibrium between chemical formation and mechanical removal [8]. The tribofilm on Cross30 was identified completely covering the contact area, indicating the growth rate was sufficient to mitigate wear. More characterization details have been published by $\mathrm{Hsu}$ et al. [27] in a previous paper, which indicated that the formation of tribofilm can be encouraged by the LST patterns. In summary, the combination of lubricant retention and tribofilm generation appears to reduce wear for all textures but is most effective with the Cross 30 pattern.

\subsection{Contact simulation}

To better understand the causes of the tribofilm formation on the bearings, the pressure distribution was analyzed by contact simulation. According to a series of in-situ measuring experiments by Gosvami et al. [22], the growth rate of tribofilm increases five-fold when increasing the contact pressures from 3 to $5 \mathrm{GPa}$, and the formation rate will be saturated above around 6.5 GPa. Consequently, each node from the simulation results has been classified by pressure value range. The parts of the contact area that experience normal stress between 3 and $7 \mathrm{GPa}$ are expected to be suitable for the formation of the protecting tribofilm.

The area of contact for the Dimple200 and Cross30 samples is shown in Fig. 5 and the overall contact area coverage for all samples is represented in Fig. 6(a). In Fig. $6(\mathrm{~b})$, the proportion of the nodes that experience contact pressures in the indicated ranges is presented. The pressure distribution on the dimple patterns is similar to the untextured reference, and higher stress can be found surrounding the dimples. When the 

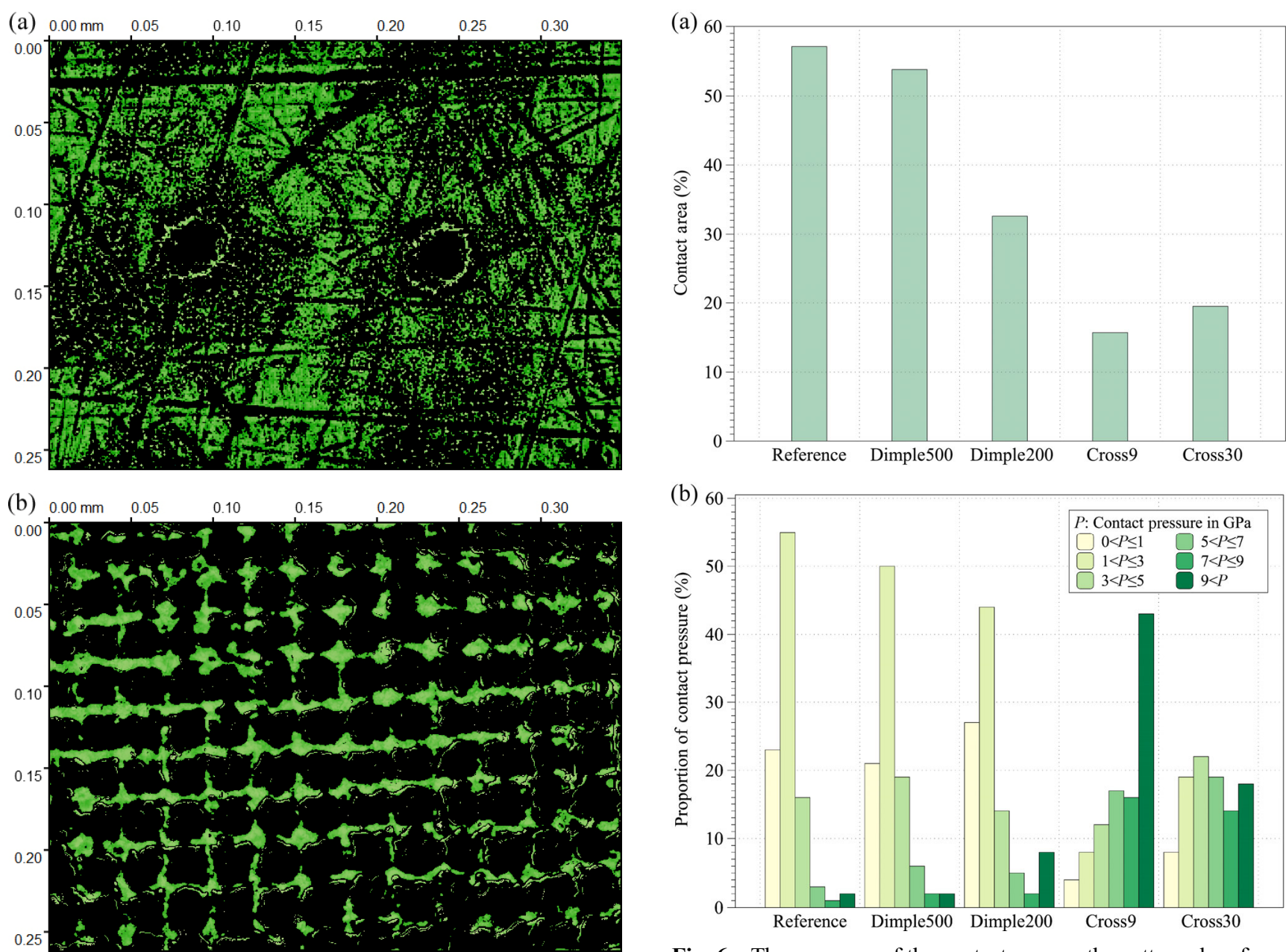

Fig. 5 The contact area of the bearing washers by the results of the contact simulations of (a) the dimple pattern with the periodicity of $200 \mu \mathrm{m}$ and (b) the cross pattern with the periodicity of $30 \mu \mathrm{m}$. The contact area is shown in green.

periodic interval decreases from 500 to $200 \mu \mathrm{m}$, the total contact area decreases. The topographical spikes observed around the dimples, which were caused by the LST, lead to higher pressure spikes which affect the full pressure distribution. This increase of contact pressure can be identified by the shift of the histogram chart to the right. The cross patterns are shown to have more higher-pressure regions due to the overall smaller contact area. Again, the shape of the histogram chart shifts to the right, indicating a greater area with high contact pressure. Compared to the dimples, the cross patterns demonstrated a greater difference in contact geometry with respect to the untextured sample. With the cross patterns, the effect of pattern geometry dominates over the surface roughness in controlling the contact stress.

Fig. 6 The coverage of the contact area on the patterned surfaces and the reference by BEM simulation (a), and the proportion of the contact pressure within the contact area (b). $(P$ : contact pressure in $\mathrm{GPa}$ )

Despite the growth rate of tribofilm increasing when the contact pressure is greater, higher contact stress can also cause more wear. The pattern Cross9 has a distinct peak showing a high percentage of nodes with pressure greater than 9 GPa (see Fig. 6(b)). While both of the cross patterns have higher contact pressure, especially in the range between 5 to $7 \mathrm{GPa}$, the pressure value of Cross9 was probably beyond the optimum pressure range for ZDDP promotion, thus leading to a higher wear rate. On the contrary, Cross30 enhanced the formation of tribofilm with sufficient pressures, but without the excessive pressures that would further increase wear.

\subsection{Fatigue lifetime evaluation}

Following the results of the wear evaluation, the 
Cross30 textured sample was selected for the fatigue lifetime experiments. Compared to the reference (untextured) bearings, no macroscopic abrasive or adhesive wear was observed on the wear track, and only pitting cracks could be found, as shown in Fig. 7. Fatigue damages occurred on either the washers or the balls, and the contour of the laser patterns can still be identified. A comparison of the fatigue lifetime by using the Weibull distribution is shown in Fig. 8. The Weibull slopes of the reference and Cross30 are similar, being 1.3 and 1.37, respectively. Since the distributions are parallel to each other, the damage mechanisms for both surface types are identical. Compared to the reference, the slope of Cross30 shifts to the right, indicating an increase of fatigue lifetime by a factor of three. Furthermore, the values were in accordance with the slope expected for cases of RCF [2].

The use of LST in rolling element bearings is still rare compared to other machine components, due to concern about their potential detrimental effect on RCF life [12]. It is evident that the increase of surface roughness by LST (see Table 4) can lead to higher contact stresses. However, the test results show no negative effect on the fatigue lifetime of the ball

(a)

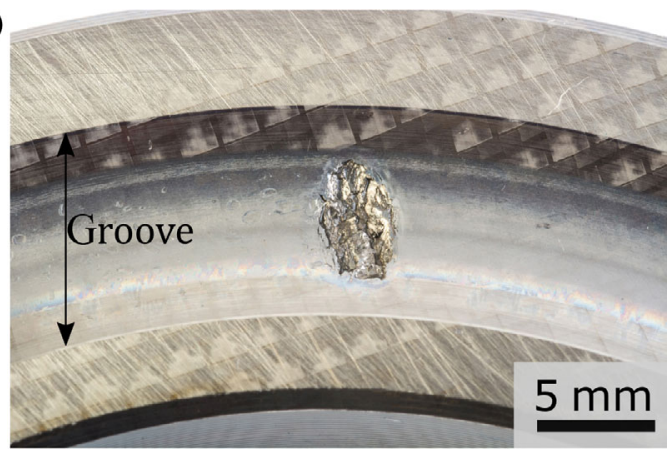

(b)

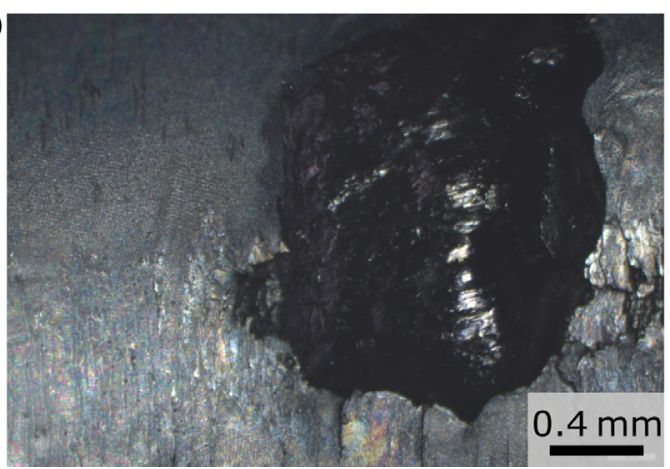

Fig. 7 Pitting damage on Cross 30 of the fatigue test (a), and an enlargement (b). The pit occurred in the groove of a bearing washer with a diameter of approximately $3 \mathrm{~mm}$.

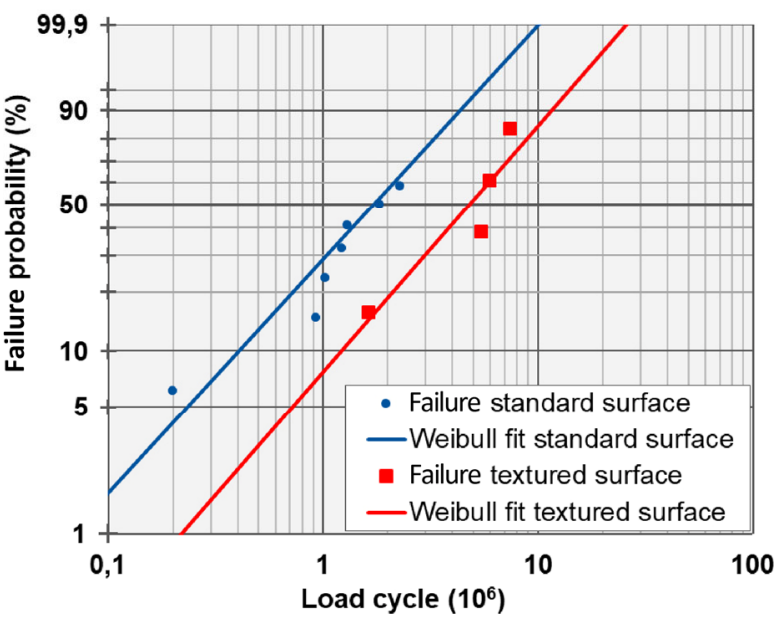

Fig. 8 Weibull distribution of the fatigue tests of the reference and the Cross 30 laser textured thrust rolling bearing.

bearings. In contrast to the concerns, the LST surfaces achieved a significantly longer fatigue lifetime, and with better wear protection. Therefore, the use of LST in ball and roller bearings should be considered, with the aid of further investigations into their use under different operating conditions and geometries.

Although friction is generally one of the main factors for the occurrence of $\mathrm{RCF}$, there was no notable difference between Cross 30 and the reference, with the values of friction coefficient being in the same range for both cases. Accordingly, the longer RCF life can be attributed to the enhancement of the anti-wear tribofilm formation and the capacity of the textured pockets that supplied sufficient lubrication.

\section{Conclusions}

In summary, the LST patterns make the surface able to retain lubricants within the contact, which ensures sufficient lubrication under such high-load conditions. Furthermore, the growth of the ZDDP tribofilm promoted by LST prevents direct contact between surfaces that reduce wear.

The conclusions for the tribological performance based on the tests and simulations carried out are:

1) A three-fold increase in fatigue lifetime was demonstrated for the laser textured thrust rolling bearings with cross periodic patterns. This is attributed to the ability of the LST patterns to retain lubricants within the contact, which ensures sufficient lubrication under such high-load conditions, combined with 
the enhanced formation of the ZDDP tribofilm that prevents direct contact between surfaces. LST has been proven to reduce wear of roller bearings in the boundary lubrication regime.

2) Geometry and area density of the laser patterns alter the tribological performances. A higher area density of the patterns leads to a higher roughness, and thus higher contact stresses. Both the $S_{\mathrm{k}}$ and $S_{\mathrm{vk}}$ parameters of the Abbott-Firestone curve (rather than $S_{\mathrm{vk}}$ alone) should be involved for assessing the ability for lubricant storage when the geometry of the LST patterns is different.

3) An increase of the contact pressure enhances the formation of ZDDP tribofilm on the cross patterns. However, high LST area density led to excessively high contact stress at the texture peaks, negating the beneficial effect and causing a higher wear rate.

\section{Acknowledgements}

The present work is supported by Deutsche Forschungsgemeinschaft (DFG) in the priority program SPP 1551 "Resource efficient machine elements" (GA 1706/2-2, Ja1940/2-2). This work is also supported by the government of Lower Austria for the endowed professorship tribology at TU Vienna (No. WST3F-5031370/001-2017). The authors also acknowledge the support by "Austrian COMET-Programme" (Project InTribology, No. 872176) under the scope of K2 $X$ Tribology and were developed in collaboration with the "Excellence Centre of Tribology" (AC2T research $\mathrm{GmbH})$.

Open Access This article is licensed under a Creative Commons Attribution 4.0 International License, which permits use, sharing, adaptation, distribution and reproduction in any medium or format, as long as you give appropriate credit to the original author(s) and the source, provide a link to the Creative Commons licence, and indicate if changes were made.

The images or other third party material in this article are included in the article's Creative Commons licence, unless indicated otherwise in a credit line to the material. If material is not included in the article's Creative Commons licence and your intended use is not permitted by statutory regulation or exceeds the permitted use, you will need to obtain permission directly from the copyright holder.

To view a copy of this licence, visit http://creativecommons.org/licenses/by/4.0/.

\section{References}

[1] Rycerz P, Olver A, Kadiric A. Propagation of surface initiated rolling contact fatigue cracks in bearing steel. Int $J$ Fatigue 97: 29-38 (2017)

[2] Sadeghi F, Jalalahmadi B, Slack T S, Raje N, Arakere N K. A review of rolling contact fatigue. $J$ Tribol 131: 041403 (2009)

[3] Johnson K L, Keer L M. Contact Mechanics. J Tribol 108: 659 (1986)

[4] Richard Booser E. Tribology Data Handbook. 2010

[5] Hsu S M. Boundary lubrication: Current understanding. Tribol Lett 3: 1-11 (1997)

[6] Etsion I. State of the Art in Laser Surface Texturing. J Tribol Trans ASME 127: 248-253 (2005)

[7] Gachot C, Rosenkranz A, Hsu S M, Costa H L. A critical assessment of surface texturing for friction and wear improvement. Wear 372-373: 21-41 (2017)

[8] Spikes H. The history and mechanisms of ZDDP. Tribol Lett 17: 469-489 (2004)

[9] Martin J M, Grossiord C, Le Mogne T, Igarashi J. Transfer films and friction under boundary lubrication. Wear 245: 107-115 (2000)

[10] Erdemir A. Review of engineered tribological interfaces for improved boundary lubrication. Tribol Int 38: 249-256 (2005)

[11] Kovalchenko A, Ajayi O, Erdemir A, Fenske G, Etsion I. The effect of laser surface texturing on transitions in lubrication regimes during unidirectional sliding contact. Tribol Int 38: 219-225 (2005)

[12] Rosenkranz A, Grützmacher P G, Gachot C, Costa H L. Surface Texturing in Machine Elements-A Critical Discussion for Rolling and Sliding Contacts. Adv Eng Mater 21: 1900194 (2019)

[13] Rosenkranz A, Stratmann A, Gachot C, Burghardt G, Jacobs G, Mücklich $\mathrm{F}$, et al. Improved wear behavior of cylindrical roller thrust bearings by three-beam laser interference. $A d v$ Eng Mater 18: 854-862 (2016)

[14] Rosenkranz A, Martin B, Bettscheider S, Gachot C, Kliem H, Mücklich F. Correlation between solid-solid contact ratios and lubrication regimes measured by a refined electrical resistivity circuit. Wear 320: 51-61 (2014)

[15] Wang Z, Gu L, Li L. Experimental studies on the overall 
efficiency performance of axial piston motor with a laser surface textured valve plate. Proc Inst Mech Eng Part B J Eng Manuf 227: 1049-1056 (2013)

[16] Ryk G, Kligerman Y, Etsion I. Experimental investigation of laser surface texturing for reciprocating automotive components. Tribol Trans 45: 444-449 (2002)

[17] Bancroft G M, Kasrai M, Fuller M, Yin Z, Fyfe K, Tan K H. Mechanisms of tribochemical film formation: Stability of tribo- and thermally-generated ZDDP films. Tribol Lett 3: 47-51 (1997)

[18] Zhang Z, Yamaguchi E S, Kasrai M, Bancroft G M. Tribofilms generated from ZDDP and DDP on steel surfaces: Part 1, growth, wear and morphology. Tribol Lett 19: 211-220 (2005)

[19] Stratmann A, Jacobs G, Hsu C-J, Gachot C, Burghardt G. Antiwear tribofilm growth in rolling bearings under boundary lubrication conditions. Tribol Int 113: 43-49 (2017)

[20] Gachot C, Hsu C, Suárez S, Grützmacher P, Rosenkranz A, Stratmann A, Jacobs G. Microstructural and Chemical Characterization of the Tribolayer Formation in Highly Loaded Cylindrical Roller Thrust Bearings. Lubricants 4: 1-11 (2016)

[21] Martin J M, Onodera T, Minfray C, Dassenoy F, Miyamoto A. The origin of anti-wear chemistry of ZDDP. Faraday Discuss 156: 311 (2012)

[22] Gosvami N N, Bares J A, Mangolini F, Konicek A R, Yablon D G, Carpick R W. Mechanisms of antiwear tribofilm growth revealed in situ by single-asperity sliding contacts. Science 348: 102-106 (2015)

[23] Rosenkranz A, Grützmacher P G, Murzyn K, Mathieu C, Mücklich F. Multi-scale surface patterning to tune friction under mixed lubricated conditions. Appl Nanosci 11: 751-762 (2019)

[24] Etsion I, Halperin G, Brizmer V, Kligerman Y. Experimental investigation of laser surface textured parallel thrust bearings. Tribol Lett 17: 295-300 (2004)

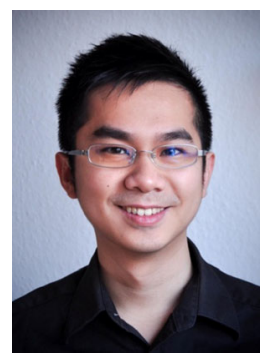

Chia-Jui HSU. He is a tribologist doing research at Vienna University of Technology. He has a background in both mechanical engineering and material science. His current study
[25] Vlădescu S C, Olver A V., Pegg I G, Reddyhoff T. Combined friction and wear reduction in a reciprocating contact through laser surface texturing. Wear 358-359: 51-61 (2016)

[26] He D, Zheng S, Pu J, Zhang G, Hu L. Improving tribological properties of titanium alloys by combining laser surface texturing and diamond-like carbon film. Tribol Int 82: 20-27 (2015)

[27] Hsu C-J, Stratmann A, Rosenkranz A, Gachot C. Enhanced Growth of ZDDP-Based Tribofilms on Laser-Interference Patterned Cylinder Roller Bearings. Lubricants 5: 39 (2017)

[28] Vrbka M, Šamánek O, Šperka P, Návrat T, Křupka I, Hartl M. Effect of surface texturing on rolling contact fatigue within mixed lubricated non-conformal rolling/sliding contacts. Tribol Int 43: 1457-1465 (2010)

[29] Lasagni A, Holzapfel C, Weirich T, Mu F, Mücklich F. Laser interference metallurgy: A new method for periodic surface microstructure design on multilayered metallic thin films. Appl Surf Sci 253: 8070-8074 (2007)

[30] Dowson D, Higginson G R, Whitaker A V. Elastohydrodynamic lubrication: A survey of isothermal solutions. J Mech Eng Sci 4: 121-126 (1962)

[31] Lubrecht A A, Venner C H, Colin F. Film thickness calculation in elasto-hydrodynamic lubricated line and elliptical contacts: The Dowson, Higginson, Hamrock contribution. Proc Inst Mech Eng Part J J Eng Tribol 223: 511-515 (2009)

[32] Stratmann A, Jacobs G, Hsu C, Gachot C, Burghardt G. Antiwear tribo film growth in rolling bearings under boundary lubrication conditions. Tribiol Int 113: 43-49 (2017)

[33] Polonsky I A, Keer L M. A numerical method for solving rough contact problems based on the multi-level multisummation and conjugate gradient techniques. Wear 231: 206-219 (1999)

[34] Petropoulos G P, Torrance A A, Pandazaras C N. Abbott curves characteristics of turned surfaces. Int J Mach Tools Manuf 43: 237-243 (2003)

is focusing on surface engineering, particularly on laser surface texturing and antiwear tribofilm. Moreover, microstructural and chemical characterization methods such as SEM, Raman, and nano-indentation are also his expertise. 